Katarina Z. Stamenković ${ }^{1}$

https://doi.org/10.46630/phm.13.2021.49

Universität in Niš

Philosophische Fakultät

Lehrstuhl für deutsche Sprache und Literatur

\title{
DIE KOMPONENTE MAGEN / ŽELUDAC IN DEUTSCHEN UND SERBISCHEN PHRASEOLOGISMEN
}

\begin{abstract}
Die vorliegende Arbeit vergleicht und analysiert deutsche Phraseologismen mit der Komponente Magen mit den serbischen Äquivalenten. Die Arbeit soll die Unterschiede und Ähnlichkeiten der Phraseologismen zeigen, aber gleichzeitig werden diese nach dem Äquivalenzgrad in verschiedene Klassen gegliedert, was auch das Ziel der Arbeit darstellt. Nach der Klassifizierung nach dem Äquivalenzgrad erfolgt eine Einteilung in drei semantische Gruppen. Die Arbeit basiert auf der kontrastiven Methode und kann als Hilfe für Germanistikstudenten dienen, aber auch im Fremdsprachenunterricht Gebrauch finden. Es wurden ein- und zweisprachige Wörterbücher zur Zusammenstellung des Korpusteils verwendet, dabei wird die deutsche Sprache als Ausgangssprache und das Serbische als Zielsprache betrachtet. Die Ergebnisse zeigen, dass nur ein geringer Grad der Übereinstimmung auftritt, da nur 4 Beispiele Volläquivalenz aufweisen. Die größte Gruppe bilden die Phraseologismen mit Nulläquivalenz mit 12 Beispielen. Insgesamt wurden 21 Beispiele gefunden.
\end{abstract}

Schlüsselwörter: Magen, želudac, Somatismen, Äquivalenz, Phraseologismen

\section{Einführung}

In der alltäglichen Kommunikation sind Phraseologismen unumgänglich. Es ist nicht immer einfach sie zu identifizieren, sie müssen erstmals erkannt, dann verstanden und danach erst aktiv verwendet werden. Aus diesem Grund stellen sie eine besondere Herausforderung für jeden Deutschlernenden dar und sollten im Unterricht detailliert behandelt werden. Auch den Gegenstand der Phraseologie selbst darzulegen ist nicht einfach, denn schnell wird klar, dass bei der Abgrenzung der Phraseologismen von nicht phraseologischen Wortverbindungen und damit einer Bestimmung des Gegenstandes der Phraseologieforschung große Schwierigkeiten auftreten und in Abhängig-

1 katarina.stamenkovic@filfak.ni.ac.rs 
keit von den zugrunde gelegten Kriterien kann man zu den unterschiedlichsten Ergebnissen kommen (vgl. FLEISCHER 1997: 5). Obwohl sich Linguisten schon seit den 1960ern mit der Phraseologie beschäftigen, liegen die Meinungen auseinander. Da eine es eine Vielfalt an Definitionen gibt, werden nur diese angegeben, die für diese Arbeit am relevantesten sind, beginnend mit folgender:

„Phraseologisch ist eine Verbindung von zwei oder mehr Wörtern dann, wenn (1) die Wörter eine durch die syntaktischen und semantischen Regularitäten der Verknüpfung nicht voll erklärbare Einheit bilden, und wenn (2) die Wortverbindung in der Sprachgemeinschaft, ähnlich wie ein Lexem, gebräuchlich ist. Die beiden Kriterien stehen in einem einseitigen Bedingungsverhältnis: wenn (1) zutrifft, dann auch (2), aber nicht umgekehrt“ (BURGER, BUHOFER, SIALM 1982: 1).

Burger gibt zusätzlich zu der Definition noch die Anzahl der Wörter im Phraseologismus an und kennzeichnet so die „Phraseologismen im weiteren Sinne“. „Allgemein werden phraseologische Verbindungen als reproduzierbare lexikalische Sprachzeichen (Festigkeit), die mindestens zwei Wörter und höchstens einen Satz umfassen (Polylexikalität) definiert" (BURGER 2003: 11). Kommt noch die Eigenschaft der Idiomatizität hinzu, das heißt, kann die Gesamtbedeutung nicht aus der Bedeutung der einzelnen Elemente erschlossen werden, dann spricht man von „Phraseologismen im engeren Sinne" (vgl. ebd.).

\section{Burger erweitert seine Definition,}

„sie bestehen aus mehr als einem Wort und die Wörter sind nicht für dieses eine Mal zusammengestellt, sondern es handelt sich um Kombinationen von Wörtern, die Deutschsprechende in genau dieser Kombination kennen. Solche Ausdrücke nennt man Phraseologismen. Die lexikalischen Bestandteile nennen wir Komponenten“ (2003: 11 - 12).

Auch Pilz beschäftigt sich mit der Problematik und seiner Meinung nach ist ein Phraseologismus ,eine Wortgruppe, die aus mindestens zwei Wörtern besteht, die getrennt geschrieben werden“" (1978: 31).

Jedoch gibt es noch eine Gruppe der Phraseologismen, die in der Arbeit noch nicht definiert wurden. Diese besondere Gruppe bilden die „Einwortphraseologismen, Einwortidiome, Einwortphraseme“. Sie sind sprachliche Einheiten, die weitgehend die phraseologischen Merkmale der Idiomatizität, Stabilität, Lexikalisierung und Reproduzierbarkeit (vgl. FLEISCHER 1997: 249; BURGER 2003: 17) aufweisen, aber das formale Kriterium der Polylexikalität nicht erfüllen. Daher werden sie meist aus der Gruppe der Phraseologismen ausgeschlossen, wie auch in dieser Arbeit.

Die Mehrheit der Forscher versucht die Phraseologismen zu klassi- 
fizieren, jedoch wirft dies Klassifikationsprobleme auf. Es werden sehr unterschiedliche Klassifikationskriterien vertreten: es gibt syntaktische, semantische oder auch pragmatische Klassifikationsvorschläge; meistens gewinnt von diesen diejenige die Oberhand, die aus der Sicht der gegebenen Untersuchung am relevantesten ist (vgl. FORGÁS 2009: 131). Diese Arbeit widmet sich nicht der Klassifizierung der Phraseologismen, da diese für den Vergleich nicht relevant ist.

\section{Somatismen}

$\mathrm{Da}$ in dieser Arbeit die Komponente Magen in den deutschen und die Komponente želudac in den serbischen Phraseologismen behandelt wird, ist es notwendig die Somatismen, die eine Unterklasse zu den Phraseologismen bilden, zu erläutern. Als solche bezeichnet man „relativ feste polylexikalische sprachliche Einheiten mit mindestens einer Körperbezeichnung als einer ihrer Konstituenten" (STAFFELDT, ZIEM 2008: 456). Die Bezeichnungen für Körperteile gehören zum ältesten Wortschatz jeder Sprache, dementsprechend gehören auch die serbische und deutsche Sprache dazu und die darauf basierten Metaphern, sowie der Bezug zum menschlichen Körper, spielen sie eine wichtige Rolle in der Phraseologie (PALM 1997: 40). A. D. Rajchstejn (zit. nach KROHN 1994: 21) stellt fest, dass die somatischen Phraseologismen 1520\% aller phraseologischen Einheiten des Deutschen ausmachen. Auch nach Heringer machen Somatismen, auch Körperteilidiome genannt, bis zu 20 Prozent aller idiomatischen Wortverbindungen des Deutschen aus (2004: 176).

„Die somatischen Phraseologismen dienen gewöhnlich als Ausdruck von emotionalen, mentalen Eigenschaften und verschiedenen Handlungen des Menschen, widerspiegeln sein Verhältnis zur Umwelt und drücken die traditionelle Symbolik der Körpersprache sowie lokale oder allgemein verbreitete Traditionen und Aberglauben aus“"(FÖLDES 1985: 21).

Aus dieser Definition geht hervor, warum die Somatismen unumgänglich in jeder Sprache sind. Jeder Mensch zeigt seine Emotionen durch seine Sprache, oft begleitet von Mimik und Gestik, wie in den Beispielen Hand aufs Herz im Deutschen oder mit dem entsprechenden Äquivalent im Serbischen ruku na srce (MRAZOVIĆ, PRIMORAC 1981: 380). Am Beispiel von Somatismen lässt sich exemplarisch veranschaulichen, welchen Einfluss körperliche Aspekte auf Denken und Sprache ausüben (STAFFELDT, ZIEM 2008: 464).

Wie schon gezeigt sind Somatismen eine spezifische Klasse von Phraseologismen. Sie können einen Körperteil, ein Körperorgan oder sogar Körperflüssigkeiten als Komponente enthalten. Es muss sich also nicht nur um sichtbare Teile des Körpers handeln. 
Etymologisch betrachtet bedeutet griech. „soma“: Leib, Körper und „logos"Wort und Kunde, daher "Somatologie“: Die Lehre von den Eigenschaften des menschlichen Körpers (vgl. RÖHRICH 2004: 1371).

Körperteilbezogene Phraseologismen zeigen sowohl im Deutschen, als auch im Serbischen eine hohe sprachliche Produktivität und bilden einen wichtigen Teil des phraseologischen Lexikons oder Wörterbuchs in diesen Sprachen (vgl. ÖZBAY 2011: 72; ŠTRBAC, ŠTASNI 2017: 9). Es muss jedoch hervorgehoben werden, dass die Körperteile in verschiedenen Sprachen verschiedene Symbolbedeutungen haben. Somatismen können sich von Kulturgemeinschaft zu Kulturgemeinschaft unterscheiden, da solche Wortverbindungen stark unter Kulturfärbung der betreffenden Gemeinschaft stehen und zum Teil aus kulturhistorischen Ereignissen entstanden sind (ÖZBAY 2011: 73). Eine detaillierte Beschreibung folgt im Analyseteil der Arbeit.

Auch diese Phraseologismen haben dieEigenschaften der Idiomatizität, Stabilität, Lexikalisierungund Polylexikalität(vgl.STAFFELDT, ZIEM2008:460). Somatismen sind Phraseologismen, die als feste Wortverbindung im alltäglichen Sprachgebrauch besonders in der gesprochenen Sprache benutzt werden; wie z.B. im Deutschen „einen langen Arm haben“ (weitreichende Macht besitzen), „die Hände über dem Kopf zusammenschlagen“ (entsetzt sein, sein Entsetzen deutlich zeigen) (ÖZBAY 2011: 73). Wie schon erwähnt werden Somatismen in verschiedenen Formen verwendet. „Eine Gruppe der Somatismen bringt Emotionen zum Ausdruck, denn die Körperteile versinnbildlichen ein bestimmtes Gefühl und enthalten häufig eine Metapher" (BURGER 2003: 87), wie zum Beispiel kalte Füße bekommen mit der Bedeutung ,Angst haben der , unsicher werden.

Daneben gibt es viele Somatismen mit einer metonymischen Bedeutung. „In solchen Phrasemen steht der Körperteil für den ganzen Menschen und in diesen Somatismen erscheint die Stilfigur Synekdoche" (BURGER 2003: 81), wie im Beispiel ein kluger Kopf mit der Bedeutung ,klug sein` oder ,fachkompetent sein.

Die Kinegramme bilden eine weitere Gruppe der Somatismen. Somatismen sind oft Kinegramme. Diese sind solche sprachliche Einheiten, deren Bedeutung einen emblematischen Charakter hat. Sie bezeichnen einen Ausdruck der Bewegung, Mimik oder Gestik (vgl. STAFFELDT, ZIEM 2008: 461), wie in dem folgenden Beispiel mit den Achseln zucken als ,Geste der Ratlosigkeit'.

\section{3. Äquivalenz}

In dieser Arbeit werden zwei Sprachen miteinander verglichen, daher ist der Begriff Äquivalenz ein wichtiger Aspekt. Da es verschiedene Auffassungen zu der Definition der Äquivalenz gibt, werden an dieser Stelle nur diese 
angegeben, die für die Arbeit am relevantesten sind.

„Unter Äquivalenz verstehen wir die kommunikative Entsprechung zwischen Ausgangs- und Zielsprache einer Einheit, diese durch maximale Übereinstimmung von Denotat, Konnotat und Funktionalität, einschließlich formaler Struktur und Komponentenbestand, zu erreichen ist" (HENSCHEL 1993: 137).

Auch Günther ist der Meinung, dass „Äquivalenz ganz allgemein als Übereinstimmung sprachlicher, phraseologischer Einheiten, in verschiedenen Sprachen oder Varietäten definiert wird“ (1990: 26). Diese Übereinstimmung wird auf verschiedene Kriterien, in der Regel auf Form und Bedeutung bezogen (vgl. KOLLER 2007: 606). Die kontrastive Linguistik, in deren Bereich die vorliegende Arbeit fällt, bleibt oft auf dieser denotativ-strukturellen Ebene beschränkt (Ebd.). Generell kann man sagen, dass versucht wird einer Äußerung in der Ausgangssprache Äquivalente in der Zielsprache zuzuordnen. In dieser Arbeit wird die deutsche Sprache als Ausgangssprache betrachtet, während die serbische Sprache als Zielsprache zu betrachten ist. Nach Worbs (zit. nach BREHMER 2009: 147) sind es v.a.

„fünf Eigenschaften von Phraseologismen, die einen Einfluss auf die Bestimmung des Äquivalenzgrades ausüben: (1) ihre formativische Mehrgliedrigkeit (Polylexikalität, d.h. Zusammensetzung aus mehreren Komponenten, sodass auch die formale Struktur für die Bestimmung der Übereinstimmung zweier kontrastierter Einheiten zu berücksichtigen ist); (2) Besonderheiten der phraseologischen Bedeutung; (3) ihre Bildhaftigkeit; (4) ihre Expressivität sowie (5) ihre Stabilität und Reproduzierbarkeit.“

In der vorliegenden Arbeit wird jeweils die Voll-, Teil- und Nulläquivalenz angeführt. Eine Einstufung als nulläquivalent erfolgt, wenn die phraseologische Bedeutung zweier Einheiten nicht mindestens partiell übereinstimmt (vgl. Juska-Bacher 2006: 27). Aber auch das gänzliche Fehlen einer entsprechenden phraseologischen Einheit wird als Nulläquivalenz angesehen, wie auch der Ersatz durch einen anderen Phraseologismus. Die rein semantische Äquivalenz wird in der Statistik zur Nulläquivalenz gezählt. Manche Autoren führen die rein semantische Äquivalenz als zusätzliche Gruppe ein, diese Arbeit richtet sich aber nach der Dreiteilung, von Földes (1996) oder Korhonen (2007). „Während der Pol der Volläquivalenz durch eine Überschneidung aller untersuchten Kriterien relativ einfach zu definieren ist, bereiten die Abgrenzung von Null- und Teiläquivalenz und die Feinstrukturierung des breiten Mittelfelds der Teiläquivalenz größere Probleme“ (Juska-Bacher 2006: 26). Die größten Unterschiede bei den gefundenen Phraseologismen in dieser Arbeit kamen im lexikalischen Bereich vor, darauf folgte der grammatische Bereich. Nach Földes erfolgt die Teiläquivalenz, wenn es zur „Gleichheit der Gesam- 
tbedeutung und des syntaktischen Modells bei nicht genauer Übereinstimmung im Komponentenbestand“ (1996: 18) kommt. Da die Volläquivalenz, die kleinste Gruppe bildet wird sie als letzte behandelt. Korhonen versteht unter Volläquivalenz, dass „alle wesentlichen Äquivalenzparameter miteinander übereinstimmen“ (2007: 578) müssen. Diese Definition wird auch in dieser Arbeit übernommen. Burger, Buhofer, Sialm sprechen von einer totalen Äquivalenz, „Totale Äquivalenz bedeutet Äquivalenz in der Bedeutung, im lexikalischen Bestand, in der Bildhaftigkeit, den stilistischen Werten und in Bezug auf die grammatische Struktur“ (1982: 295).

\section{Phraseologismen mit der Komponente Magen / želudac}

Die gefundenen Phraseologismen werden nach ihrem Äquivalenzgrad sortiert. Zuerst werden die Phraseologismen mit Nulläquivalenz angegeben, da deren Anzahl in dieser Arbeit die zahlreichste ist und dazu gezählt werden auch Phraseologismen, die kein entsprechendes Äquivalent im Serbischen haben. In diesem Falle wird versucht ein Beispiel mit semantischer Äquivalenz anzugeben. Darauf folgen Teiläquivalenz und Volläquivalenz.

Die Phraseologismen an sich werden wie folgt strukturiert, an erster Stelle wird unter a) der deutsche Phraseologismus angegeben, gleich darauffolgend der Autor in abgekürzter Form in runden Klammern. Falls es mehrere Variationen des Phraseologismus gibt, werden diese durch den Schrägstrich getrennt, angegeben. In der Arbeit werden folgende Wörterbücher zurZusammenstellung des deutschen Korpusteils verwendet und sie werden wie folgt gekürzt: Dudenredaktion (Hrsg.): Duden. Bd.11: Redewendungen: Wörterbuch der deutschen Idiomatik. Im Weiteren wird die Abkürzung D in runden Klammern verwendet. Lutz Röhrich: Lexikon der sprichwörtlichen Redensarten. In der Arbeit wird die Abkürzung $\mathrm{R}$ in runden Klammern verwendet. Renate Wahrig-Burfeind (Hrsg.): Wahrig: Deutsches Wörterbuch. In der Arbeit wird im Weiteren die Abkürzung $\mathrm{W}$ in runden Klammern verwendet. Serbische Äquivalente wurden in folgenden Wörterbüchern gefunden: Pavica Mrazović; Ružica Primorac: Deutsch - serbokroatisch phraseologisches Wörterbuch: Deutsche idiomatische Wendungen und ihre serbokroatischen Entsprechungen. In der Arbeit wird für dieses Wörterbuch die Abkürzung MP in runden Klammern verwendet. Đorđe Otašević: Frazeološki rečnik srpskog jezika. In der Arbeit wird für dieses Wörterbuch die Abkürzung $\mathrm{O}$ in runden Klammern verwendet.

Nach dem deutschen Phraseologismus und der Quelle wird in der nächsten Zeile die entsprechende Bedeutungserklärung auf Deutsch angeführt. Diese Erklärungen, falls keine Abkürzung vorzufinden ist, sind Erklärungen der Autorin. In der darauffolgenden Zeile, unter b) steht das entsprechende Äquivalent des Phraseologismus auf Serbisch, darunter wieder die Erklärung 
des Phraseologismus. Letztlich wird dem Phraseologismus die Äquivalenzstufe zugeordnet und es folgt eine kurze Analyse des deutschen und serbischen Phraseologismus. Falls mehrere Äquivalente im Serbischen gefunden worden sind, werden diese in einer Fußnote angegeben, jedoch nicht in der Statistik berücksichtigt.

\subsection{Nulläquivalenz}

1. a) jemandem wie Blei im Magen liegen (W, 968)

jemandem schwer zu schaffen machen, jemanden bedrücken / quälen; Übelkeit verursachen vom Essen

b) biti nekome kost u grlu $(\mathrm{O}, 170)$

kvariti nekome raspoloženje, biti nekome nepodnošljiv, nesimpatičan (MP, 560)

Die Komponente Magen ist im serbischen Äquivalent nicht vorhanden, die Nomen kost auf Deutsch Knochen und grlo Hals sind dagegen im serbischen Phraseologismus vertreten.

2. a) jemandem auf den Magen schlagen (D, 488; W, 968)

zu Magenbeschwerden / Übelkeit / Unwohlsein führen, jemandem die Laune verderben

b) biti nekome kost u grlu $(\mathrm{O}, 170)$

kvariti nekome raspoloženje, biti nekome nepodnošljiv, nesimpatičan $(M, 560)$ Auch in diesem Beispiel gibt es keine gemeinsamen Bestandteile. Das gleiche serbische Äquivalent wie im ersten Beispiel wurde angegeben, da es auch zu dieser Situation passt.

3. a) jemandem auf den Magen liegen (W, 968)

unausstehlich / unsympathisch sein

b) biti nekome trn u oku $(\mathrm{O}, 921)$

biti nekome velika smetnja

Keine Äquivalente konnten in den Phraseologismen identifiziert werden.

4. a) jemandem hängt der Magen schief ${ }^{2}$ / in den / bis zu den Kniekehlen (D, 487; W, 968) jemand hat Hunger

b) gladan kao vuk (MP, 559)

biti veoma gladan Es handelt sich um Nulläquivalenz. Keine Bestandteile der Phraseologismen stimmen überein.

5. a) sich den Bauch / Magen / vollschlagen (D, 805)

viel essen

b) napuniti svako crevo (MP, 102)

2 vgl. fr. J'ai l'estomac dans les talons (wört.: Der Magen steckt mir in den Fersen) (Röhrich, 989). 
dobro se najesti

Es gibt keine gemeinsamen Komponenten. Es handelt sich um Nulläquivalenz.

6. a) jemanden im Magen haben ${ }^{3}$ (D, 488)

jemanden nicht leiden können

b) mrzeti nekoga iz dna duše $(\mathrm{O}, 513)$

mrzeti u največoj meri

Auch in diesen Phraseologismen gibt es keine gemeinsamen Bestandteile. Das Nomen Magen konnte im serbischen Äquivalent nicht angegeben werden. Es wird das Nomen $d u s ̌ a$ verwendet.

7. a) ein Loch im Magen haben (W, 953)

sehr viel essen

b) vreča bez dna $(\mathrm{O}, 128)$

mnogo jesti

In der gefundenen phraseologischen Einheit in der serbischen Sprache gibt es keine gemeinsamen Bestandteile.

8. a) seinem Magen keine Stiefmutter sein (MP, 559)

gern und viel essen

b) biti prijatelj svom stomaku (MP, 559)

voleti dobar zalogaj

Im serbischen Phraseologismus werden die Nomen stomak und prijatelj auf Deutsch Bauch und Freund verwendet, im deutschen Phraseologismus dagegen das Nomen Magen und Stiefmutter.

9. a) da wird die Katze den Magen nicht forttragen (MP, 560)

wird beim Anblick einer reichlichen Mahlzeit gesagt (R, 989) / sehr viel essen

b) najeo si se kao prosjak na zadušnice (MP, 560) previše jesti

Es handelt sich um Nulläquivalenz, da kein passendes Äquivalent gefunden wurde.

10. a) lieber den Magen verrenken, als dem Wirt etwas schenken (D, 487; W, 968)

auch wenn man bereits satt ist, wird die bestellte Portion aufgegessen, da man sie bezahlen muss

b) Es gibt keine entsprechende Übersetzung.

bolje se prejesti nego ostaviti na tanjiru plaćeno jelo (MP, 560)

Da keine Übersetzung gefunden wurde, wird der Phraseologismus als Nulläquivalenz behandelt.

3 Die Wendung steht verkürzend für ,jemanden wie eine schwer verdauliche Speise im Magen haben“ (Duden, 488). 
11. a) Käse schließt den Magen (D, 394) scherzhafter Kommentar, wenn man das Essen mit einem Käsegang beschließt

b) Es gibt keine entsprechende Übersetzung. kada obrok završimo sirom Kein angemessenes Äquivalent konnte gefunden werden.

12. a) jemandem wird flau (im Magen) (W, 529)

jemandem ist unwohl

b) Es gibt keine Übersetzung. nekome je neprijatno

Da keine Übersetzung gefunden wurde, wird der Phraseologismus als Nulläquivalenz behandelt.

\subsection{Teiläquivalenz}

13. a) noch nichts im Magen / Leib haben (W, 968)

noch nicht gegessen haben

b) prilepio se nekome želudac za leđa $(\mathrm{O}, 275)$

neko odavno nije jeo

Die Komponente Magen kommt in beiden Phraseologismen vor, aber das Verb haben im deutschen Phraseologismus und das Verb prilepiti auf Deutsch ankleben nicht.

14. a) Liebe geht durch den Magen! (D, 474; W, 968)

scherzhaft, Liebe und gutes Essen gehören zusammen

b) ljubav ide kroz stomak (MP, 541)

muškarac voli onu ženu, koja mu dobro kuva Alle Elemente stimmen überein, lediglich die Nomen Magen im deutschen Phraseologismus und das Nomen stomak in dem serbischen Phraseologismus, auf Deutsch Bauch, nicht.

15. a) jemandem knurrt der Magen (D, 487; W, 968)

jemand hat Hunger

b) nekome krče creva od gladi (MP, 559)

neko je gladan

Das Verb krčati im serbischen Phraseologismus und das Verb knurren sind äquivalent. Die anderen Komponenten nicht.

16. a) die Augen sind größer als der Magen! $(\mathrm{D}, 69 ; \mathrm{W}, 968)$

4 Die Redensart findet sich bereits in einer anonymen Sammlung von 1532 mit dem Wortlaut „Die Augen seyndt weitter denn der Bauch.“ (Duden, 69). Auch vgl. frz. Il les yeux plus grands que le ventre (Röhrich 2004: 989). 
wenn man sich mehr auf den Teller gibt, als man essen kann

b) gladne oči / oči veće od stomaka (MP, 74)

uzeo je vise no što može pojesti

In beiden Phraseologismen wird das Nomen Augen bzw. oči verwendet. Jedoch wird im serbischen Phraseologismus das Nomen stomak, auf Deutsch Bauch benutzt, im deutschen Phraseologismus aber Magen.

17. a) einen guten Magen haben (W, 968)

alle Speisen vertragen können / Beleidigungen und Spott ertragen können

b) imati dobar stomak (MP, 560)

može da jede sve, nije probirljiv / podnositi uvrede, podsmeh, bez, vredjanja

Das Nomen stomak bedeutet Bauch, welches im serbischen Phraseologismus erscheint, aber im deutschen Phraseologismus wird jedoch das Nomen Magen angeführt.

\subsection{Volläquivalenz}

18. a) etwas dreht einem den Magen um (D, 487; W, 968)

etwas verursacht Übelkeit

b) nešto preokreće nekome želudac (O, 275)

nešto stvara mučninu

Alle Bestandteile stimmen überein. Die Nomen Magen und želudac, so wie die Verben drehen und preokretati.

19. a) jemandem dreht / kehrt sich bei etwas der Magen um (D, 487)

jemandem wird übel

b) okreće se nekome želudac od nečega (MP, 559; O, 275)

neko ima osećaj gađenja i oseća mučninu

Auch in diesem Beispiel sind alle Komponenten äquivalent.

20. a) einen schwachen Magen haben (W, 968)

leicht mit Magenbeschwerden zu tun haben

b) imati slab želudac

lako oboljeva od želuca, biti osetljiv na teške reči ili slike

21. a) auf nüchternem Magen (D, 487; W, 968)

Ausdruck der Verärgerung, wenn einem etwas Unangenehmes ganz unvermittelt passiert

b) na prazan želudac / stomak (MP, 560)

još i pored ostalih briga i neprijatnosti i to

Das Nomen želudac im serbischen Phraseologismus stimmt mit dem deutschen Nomen Magen überein. An dieser Stelle muss jedoch betont werden, dass das deutsche Adjektiv nüchtern mehrere Bedeutungen hat und zwar „ohne 
gegessen oder getrunken zu haben, mit leerem Magen“, „leer (Magen)“, „,nicht betrunken“" (WAHRIG-BURFEIND 2011: 1080). Somit können auch die Adjektive nüchtern und prazan „leer“ als volläquivalent bezeichnen werden.

\section{Semantische Gruppierung}

Was in der Arbeit noch angezeigt werden kann, sind die semantischen Gruppen, in die sich diese Phraseologismen eingliedern lassen. Grob kann festgestellt werden, dass der größte Teil der angeführten Phraseologismen im direkten Bezug zur Verdauung steht. Dies wiederum könnte der Grund sein, warum diese Phraseologismen ihre Verwendung öfter in der Umgangssprache finden. Auffallend ist weiter die negative Konnotation dieser Phraseologismen mit der Komponente Magen, es kann nur eine Ausnahme genannt werden und zwar der Phraseologismus Liebe geht durch den Magen. Dieser Phraseologismus enthält die Komponente Liebe, daher kommt wohl auch seine positive Konnotation, da mit Liebe immer positive Gefühle in Verbindung gebracht werden. Eine Person kocht aus Liebe zu einer anderen Person.

In der Arbeit wurden bereits Äquivalente zu den Phraseologismen mit der Komponente Magen in der serbischen Sprache gefunden. Aus diesem Grund werden an dieser Stelle in den jeweiligen Gruppen nur die deutschen Phraseologismen angegeben.

Die Phraseologismen mit der Komponente Magen können in drei Gruppen geteilt werden: Verdauung, Essen und Unwohlsein. Zu der zweiten Gruppe Essen, werden auch alle Phraseologismen gezählt, die das Gefühl von Hunger angeben. Es kann jedoch keine klare Abgrenzung zwischen den Gruppen erfolgen; mehrere Phraseologismen können sowohl im Serbischen, als auch im Deutschen zu zwei Gruppen gleichzeitig gezählt werden.

Die erste Gruppe trägt den Oberbegriff Unwohlsein, bzw. sich unwohl fühlen. Wie der Name dieser Gruppe schon verrät, haben alle Phraseologismen eine negative Konnotation. Sowohl die deutschen, als auch die serbischen Phraseologismen drücken ein Unbehagen in den folgenden Phraseologismen aus: jemandem wie Blei im Magen liegen, jemandem auf den Magen schlagen, jemandem auf den Magen liegen, jemanden im Magen haben, jemandem ist flau im Magen, einen guten Magen haben, jemandem dreht / kehrt sich bei etwas der Magen um, auf nüchternem Magen.

Die zweite Gruppe wurde mit dem Oberbegriff Verdauung gekennzeichnet. Es können gleich sechs Phraseologismen in dieser und in der ersten Gruppe auftreten. Da die Phraseologismen in dieser Gruppe keine übertragene Bedeutung haben müssen und neben dem Gefühl des Unbehagens, so auch die Verdauung beschreiben können.

jemandem wie Blei im Magen liegen, jemandem auf den Magen schlagen, einen schwachen Magen haben, jemandem ist flau im Magen, jemandem 
dreht / kehrt sich bei etwas der Magen um, auf nüchternem Magen, einen guten Magen haben

Die dritte Gruppe trägt den Oberbegriff Essen und wie bereits erwähnt wird zu viel oder zu wenig Essen zu dieser gezählt, genau wie die Umschreibung „Hunger haben“. In dieser Gruppe sind die meisten Phraseologismen aufzufinden. Phraseologismen, die zu dieser Gruppe gehören sind:

jemandem hängt der Magen schief / in den / bis zu den Kniekehlen, sich den Bauch / Magen / vollschlagen, ein Loch im Magen haben, seinem Magen keine Stiefmutter sein, da wird die Katze den Magen nicht forttragen, lieber den Magen verrenken, als dem Wirt etwas schenken, Käse schließt den Magen, noch nichts im Magen / Leib haben, jemandem knurrt der Magen, die Augen sind größer als der Magen, einen guten Magen haben.

\section{Ergebnisse /Schlussbemerkungen}

Nach der Analyse der Phraseologismen werden hier die Ergebnisse angegeben. Alle Beispiele wurden aufgezählt und in drei Äquivalenzstufen gegliedert, dabei wurden insgesamt 21 Phraseologismen mit der Komponente Magen gefunden. Bei 12 Beispielen handelt es sich um Nulläquivalenz und diese bilden die größte Gruppe. Die Teiläquivalenz folgt mit nur fünf Beispielen und mit nur einem Beispiel weniger, die Volläquivalenz mit vier Beispielen. Drei Beispiele wurden in der Arbeit angeführt, für die keine phraseologische Übersetzung gefunden wurde. Sie wurden deshalb zur Nulläquivalenz gezählt.

Es ist nicht zu bestreiten, dass die Komponente Magen bzw. želudac eine wichtige Rolle in der serbischen und deutschen Sprache spielt, jedoch geht aus der vorliegenden Arbeit deutlich hervor, dass die Komponente, $\mathrm{Ma}$ gen in den deutschen Phraseologismen häufiger vorkommt, als in den entsprechenden serbischen Übersetzungen. Interessant ist aber hervorzuheben, dass in fünf Äquivalenten anstatt der Komponente Magen die Komponente Bauch (stomak) in den serbischen Übersetzungen auftrat. Der Magen, genau wie der Bauch, steht für Nahrung und Gefühle, aber hauptsächlich für negative Gefühle. Daher ist der größte Teil der angeführten Phraseologismen an diese Bedeutung gebunden. Nur ein Beispiel hat eine positive Konnotation und zwar der Phraseologismus Liebe geht durch den Magen, da dieser neben der Komponente Magen, auch die Komponente Liebe beinhaltet. Mit der Liebe im Allgemeinen werden positive Gefühle verbunden. Wenn man in drei deutschen Phraseologismen, die Komponente Magen durch die Komponente Bauch austauschen würde, wären diese Beispiele volläquivalent.

Beide Sprachen gehören nicht derselben Sprachfamilie an und stehen nicht in direktem Kontakt zueinander, dies könnte einer der Gründe sein, weshalb Unterschiede in den Phraseologismen auftreten. Es gibt nur einen geringen Grad der Übereinstimmungen. Nur vier Beispiele weisen Volläquivalenz 
auf.

Das Ziel der Arbeit war der Vergleich der deutschen und serbischen Sprache, genauer gesagt ihrer Phraseologismen mit der Komponente Magen und želudac. Daraufhin folgte ein Versuch der semantischen Gliederung.

Um sprachliche Missverständnisse zu vermeiden, ist eine Vertiefung der Phraseologismen für den Deutschlernenden unumgänglich. Der Autor hofft deshalb, dass die Ergebnisse dieser Arbeit dem Lernenden als Hilfe zur Wortschatzerweiterung dienen können.

\section{Wörterbücher}

Dudenredaktion (Hrsg.): Duden. Bd.11: Redewendungen: Wörterbuch der deutschen Idiomatik 4. Mannheim: Dudenverlag, 2013.

Mrazović, Pavica; Primorac, Ružica: Deutsch-serbokroatisch phraseologisches Wörterbuch: Deutsche idiomatische Wendungen und ihre serbokroatischen Entsprechungen. Beograd: narodna knjiga Beograd, 1981.

Otašević, Đorđe: Frazeološki rečnik srpskog jezika. Novi Sad: Prometej, 2012.

Röhrich, Lutz: Lexikon der sprichwörtlichen Redensarten. Bd.1: A - Hampelmann. Freiburg:

Herder Verlag, 2004.

Wahrig-Burfeind, Renate (Hrsg.): Deutsches Wörterbuch. Gütersloh: Wissen-Media-Verlag, 2011.

\section{Zitierte Werke}

BREHMER 2009: BREHMER, Bernhard. „Äquivalenzbeziehungen zwischen komparativen Phraseologismen im Serbischen und Deutschen“. Südslawistik online, Nr. 1 (Januar 2009) s. 147.

BURGER, BUHOFER, SIALM 1982: BURGER, Harald; BUHOFER Annelies und SIALM Ambros. Handbuch der Phraseologie. Berlin: de Gruyter. 1982, s. 1-295.

BURGER 2003: BURGER, Harald. Phraseologie. Eine Einführung am Beispiel des Deutschen. Berlin: Erich Schmidt Verlag, 2003, s. 11-31.

FLEISCHER 1997: FLEISCHER, Wolfgang. Phraseologie der deutschen Gegenwartssprache. Leipzig: VEB Bibliographisches Institut, 1997, s. 2-249.

FÖLDES 1985: FÖLDES, Csaba. „Über die somatischen Phraseologismen der deutschen, russischen und ungarischen Sprache. Versuch einer konfrontativen Analyse“. In: Germanistisches Jahrbuch DDR - UVR / Lektorat für Deutsche Sprache und Literatur beim Kultur- und Informationszentrum der DDR in Budapest. Budapest, s. 21.

FÖLDES 1996: FÖLDES, Csaba. Deutsche Phraseologie kontrastiv. Intra- und 
interlinguale Zugänge, Heidelberg: Groos.

FORGÁCS 2009: FORGÁCS, Tamás. „Problematik der Klassifizierung phraseologischer Einheiten“. In: Földes, Csaba (Hrsg.): Phraseologie disziplinär und interdisziplinär. Tübingen: Gunter Narr Verlag, 2009, s. 131.

GÜNTHER 1990: GÜNTHER, Kurt. „Äquivalenzbezeichnungen in der Phraseologie“. In: Zeitschrift für Slawistik 35, (1990), s. 26.

HENSCHEL 1993: HENSCHEL, Helgunde. Die Phraseologie der tschechischen Sprache: Ein Handbuch. Frankfurt am Main: Peter Lang Verlag, 1993, s. 137.

HERINGER 2004: HERINGER, Hans Jürgen. Interkulturelle Kommunikation: Grundlagen und Konzepte. A. Francke Verlag: Tübingen, 2004, s. 176. JUSKA-BACHER 2006: JUSKA-BACHER, Britta. Empirisch kontrastive Phraseologie: Am Beispiel der Niederländischen Sprichwörter im Niederländischen, Deutschen und Schwedischen. Bd.23. Essen: Schneider Verlag Hohengehren Gmbh, 2006, s. 9 - 43.

KOLLER 2007: KOLLER, Werner. „Probleme der Übersetzung von Phrasemen“. Burger, Harald (Hrsg.) In: Phraseologie. Ein internationales Handbuch der zeitgenössischen Forschung. 1. Halbband. Berlin: Walter de Gruyter 2007, s. 605-606.

KORHONEN 2007: KORHONEN, Jarmo. „Probleme der Phraseologie“. Burger, Harald (Hrsg.) In: Phraseologie. Ein internationales Handbuch zeitgenössischer Forschung. 1. Halbband. Berlin: Walter de Gruyter 2007, s. 574-589.

KROHN 1994: KROHN, Karin. Hand und Fuß: eine kontrastive Analyse von Phraseologismen im Deutschen und Schwedischen. Göteburg: Acta Universitatis Gothoburgensis, 1994, s. 21-29.

ÖZBAY 2011: ÖZBAY, Recep. „Übersetzungsproblematik bei türkischen und deutschen somatischen Phraseologismen“. Firat University Journal of Social Science 21, 2 (2011), s. 70-86.

PALM 1997: PALM, Christine. Phraseologie. Eine Einführung. Tübingen: Gunter Narr Verlag, 1997, s. 1- 113.

PILZ 1981: PILZ, Klaus Dieter. Phraseologie: Redensartenforschung. Stuttgart: Metzlersche Verlagsbuchhandlung, 1981, s. 1-31.

STAFFELDT, ZIEM 2008: STAFFELDT, Sven; ZIEM, Alexander. „Körper-Sprache: Zur Motiviertheit von Körperteilbezeichnungen in Phraseologismen“. In: Sprachwissenschaft 4 (2008), s. 456-461.

ŠTRBAC, ŠTASNI 2017: ŠTRBAC, Gordana; ŠTASNI, Gordana. Somatizmi $i$ konceptualizacija stvarnosti u srpskom jeziku. Glava i njeni delovi. Novi Sad: Filozofski fakultet u Novom Sadu, 2017, str. 9. [orig.] ШТРБАЦ, Гордана; ШТАСНИ Гордана. Соматизми и концептуализација 
стварности у српском језику. Глава и юени делови. Нови Сад: Филозофски факултет у Новом Саду, 2017, стр. 9.

Katarina Z. Stamenković

\section{KOMPONENTA ŽELUDAC / MAGEN U NEMAČKIM I SRPSKIM FRAZEOLO- GIZMIMA}

Ovaj rad analizira i upoređuje nemačke frazeologizme sa komponentom Magen sa njihovim srpskim ekvivalentima. Frazeologizmi su sastavni deo svakog jezika i omogućavaju govornicima da se izraze na različite načine. Frazeologizme bi trebalo prvo prepoznati, zatim razumeti, pa tek onda aktivno koristiti. Iz tog razloga frazeologizmi predstavljaju poseban izazov u nastavi stranog jezika. Somatizmi u nemačkom i srpskom jeziku ulaze u osnovni leksički fond. Pored kontrastivne analize, cilj ovog rada je i klasifikacija frazeologizama sa komponentom Magen / želudac prema stepenu ekvivalencije. Nakon klasifikacije prema stepenu ekvivalencije, frazeologizmi su podeljeni i u tri semantičke grupe. Rad je zasnovan na kontrastivnoj metodi i može pomoći studentima germanistike, ali i u nastavi stranog jezika. Korpus je ekscerpiran iz jednojezičnih i dvojezičnih rečnika sa nemačkim kao polaznim jezikom i srpskim kao ciljnim jezikom. Samo četiri od dvadeset i jedan nađena primera pokazuju potpunu ekvivalenciju. Najveću grupu čine frazeologizmi sa nultom ekvivalencijom.

Ključne reči: želudac, Magen, somatizmi, ekvivalentnost, frazeologizmi 